\title{
Observation of a Chemical Softener's Effects on Stem-Specific Lignocellulosic Brassica napus (Type: Canola) (Cultivar: HYHEAR 3) Fiber Quality
}

\author{
Afroza Parvin, Mashiur Rahman*, Douglas J. Cattani \\ University of Manitoba, Winnipeg, Canada \\ Email: parvina@myumanitoba.ca, *mashiur.rahman@umanitoba.ca,doug.cattani@umanitoba.ca
}

How to cite this paper: Parvin, A., Rahman, M. and Cattani, D.J. (2021) Observation of a Chemical Softener's Effects on Stem-Specific Lignocellulosic Brassica napus (Type: Canola) (Cultivar: HYHEAR 3) Fiber Quality. Journal of Textile Science and Technology, 7, 112-130.

https://doi.org/10.4236/jtst.2021.73010

Received: May 2, 2021

Accepted: July 26, 2021

Published: July 29, 2021

Copyright $\odot 2021$ by author(s) and Scientific Research Publishing Inc. This work is licensed under the Creative Commons Attribution International License (CC BY 4.0).

http://creativecommons.org/licenses/by/4.0/

\section{Open Access}

\begin{abstract}
Chemical softener (Cepreton UN) is used to soften the cellulosic fiber (cotton) in the textile industries to make clothes better to touch. Therefore, this study investigated the effects of Cepreton UN on both physical (length, aspect ratio, contact angle, and moisture regain) and mechanical (load at break, elongation at break, tensile stress, young's modulus, and tenacity) properties of the lignocellulosic canola (HYREAR 3) fibers extracted from narrow, medium, and wide stems. ANOVA showed that fiber diameter had strong effects on elongation at break, load at break, tensile stress, young's modulus, and aspect ratio for all fibers. Corrgram values showed that tensile stress, young's modulus, and aspect ratio were negatively correlated to fiber diameter whereas load at break and tenacity were mostly positively correlated to fiber diameter. The fibers were treated with $2 \%$ and $10 \%$ Cepreton UN and compared with control fibers. In most cases, the fiber diameter was decreased in both $2 \%$ and $10 \%$ treated medium stem fibers. The mean values of elongation at break, load at break, tenacity, and contact angle were decreased for $10 \%$ and increased for $2 \%$ and the mean values of tensile stress, young's modulus, and aspect ratio were decreased for $2 \%$ and increased for $10 \%$ treated medium stem fibers. Moisture regain (\%) mostly decreased for $2 \%$, and increased for $10 \%$ treated fibers. Low $\mathrm{pH}$ (4.5) had an almost similar effect on fibers as 2\% Cepreton UN. Overall, 2\% Cepreton UN treatment is found to be better than $10 \%$ to make canola fibers less stiff and low $\mathrm{pH}$ was found to be an alternative softener treatment strategy.
\end{abstract}

\section{Keywords}

Softener, Cepreton UN, Load at Break, Tensile Stress, Young's Modulus, 
Tenacity, Contact Angle, Aspect Ratio, Elongation at Break, Moisture Regain

\section{Introduction}

Canola (Bassica napus) fibers, derived from plant bast, are being researched for textile and apparel applications in recent times. To maintain durability, a textile must have a certain level of mechanical strength to tolerate the wear and tear that occurs during regular use [1]. Mechanical stress on textiles produced from natural fibers such as cotton, wool, and jute is greatly influenced by machine washing [2]. Jute is considered the second most important natural bast fiber behind cotton (seed fiber) [3] [4]. The fabric texture is hardened by squeezing and fraying of the fabric surface; moreover, the fabric becomes tighter after drying in the air [2].

Surface modification of fibers can reduce/enhance moisture absorption and enhance/reduce fiber-matrix interfacial bonding, wettability, roughness, and hydrophilic features, which can improve/decrease the tensile properties of fiber cementitious composites/textile applications [5]. Fiber surface modification could be done by physical [6], chemical [7], or biological methods [8]. Chemical softeners significantly influence various fabric properties, such as roughness, bonding, wettability, tensile strength. Softeners are a type of conditioner containing cationic, anionic, or non-ionic surfactant or alkoxyalkylamide and can be applied in laundry during the rinse cycle or transferred to the textile during drying from an inert cellulosic or polyurethane substrate [9]. Bast fibers are usually stiffer because they consist of millions of microfibrils angled inside the cellulosic fibers, with the angles of cellulosic fibers being inversely proportional to stiffness [10]. Among the fibers considered, cotton has the highest cellulosic $(88 \%-96 \%)$ and lowest lignin (wood fiber content) content $(0.4 \%-1 \%)$ and thus exhibits the highest flexibility and twisting capacity. Similarly, jute contains less cellulose $(61 \%-75.5 \%)$ than cotton but more than canola (44\%) and contains more lignin $(12 \%-13 \%)$ than cotton but less than canola (19.21\%) showing less flexibility than cotton but more flexibility than canola [11] [12] [13].

When examining a textile, people generally touch the textile in an automatic manner, using their hands to assess the fabric [14]. Thus, considering the appeal to consumers, the use of softeners has diversified in recent years, with a focus on fragrance, deodorizing, and/or antibacterial qualities of the fabrics. Nonetheless, softeners still provide the primary function of softening clothes, a function that has remained unchanged over time [15].

Though the market is overflowing with many products, in this study, we applied a cationic softener (Cepreton UN) to observe its effects on stem-specific lignocellulosic canola bast fibers, as Cepreton UN primarily softens cellulosic (cotton) fibers. Cepreton UN is a concentrated cold-water-soluble cationic softener pastille and is highly popular and widely used in the textile industry [16]. 
In previous studies of our lab, we observed that the medium matured canola stem $(7-10 \mathrm{~mm})$ fibers were less stiff in terms of most of the physical and mechanical properties than immature or over mature stem fibers [17]. The current and the previous studies [17] were examined on a single type of canola fiber collected from a single cultivar (HYREAR 3), species (Brassica napus), time, and location and it would be interesting to observe how Cepreton UN affects that specific type of canola fiber. We assumed that Cepreton UN softener will improve the texture of stem-specific canola fibers. Therefore, the hypothesis of our study was "softener makes the stem-specific lingo-cellulosic canola bast fibers relatively less stiff". To test this hypothesis, we investigated the effects of Cepreton UN on stem-specific canola fiber physical and mechanical properties.

\section{Materials and Methods}

\section{Collection and retting of plant stem samples and extraction of fibers}

After harvesting, Brassica napus (type: canola) (cultivar: HYREAR 3) plant stem samples were cut by around $10 \mathrm{~cm}$ long and stored at approximately $25^{\circ} \mathrm{C}$ $\pm 2^{\circ} \mathrm{C}$ and $33 \% \pm 2 \%$ relative humidity prior to retting and physical and mechanical characterization. In this study, six batches of samples were extracted using same condition and each batch was categorized by three types of stems based on 3 different diameter ranges and each range was separated by at least $0.10 \mathrm{~mm}$. The diameters of the stems were measured by a Digital Slide Caliper. The stem diameter ranges were categorized in 2 groups; extraction-1 (E1), extraction-3 (E3), extraction-4 (E4), and extraction-6 (E6) were considered as group-1, and extraction-2 (E2) and extraction-5 (E5) were designed as group-2 fibers (Table 1). Group-1 extractions have nearly similar diameter range and so as group-2. The stems were then retted in a water bath for $48 \pm 2$ hours at $40^{\circ} \mathrm{C}$. The fibers (outer layer) were extracted from the plant stems after retting and then air dried in the lab for approximately 72 hours. The temperature and the relative humidity (RH) of that lab were maintained nearly $25^{\circ} \mathrm{C} \pm 2{ }^{\circ} \mathrm{C}$ and $33 \%$ $\pm 2 \%$, respectively.

\section{Treatment with chemical softener (Cepreton UN) of extracted fibers}

Two sets of fibers after extraction (E2 and E4) were used for softener (Cepreton UN, Achroma life enhanced) treatment. The exhaust method for Cepreton UN treatment provided by the production company for cellulosic fiber was given in Table 2 and E4 was treated following exhaust method. However, E2 was treated using a modified exhaust method (Table 2 ) by modifying time and concentration of Cepreton UN.

\section{Modification of time and concentration of Cepreton UN}

Canola fibers are lignocellulosic fibers as it has low cellulose and high lignin content compared to cotton [11] [13]. Therefore, exhaust method was slightly modified (Table 2) to get the maximum softness of lignocellulosic bast fibers. However, these parameters (Table 2) were not statistically optimized and hence, not recommended as standards for large scale utilization for canola fiber. 
Table 1. Groups of stems based on different diameters.

\begin{tabular}{|c|c|c|c|}
\hline Extractions & Stems & Diameter ranges $(\mathrm{mm})$ & Groups \\
\hline \multirow[t]{3}{*}{ E1 } & Narrow & $2.8-4.5$ & 1 \\
\hline & Medium & $4.8-7.8$ & \\
\hline & Wide & $8.0-10.0$ & \\
\hline \multirow[t]{3}{*}{ E2 } & Narrow & $2.5-6.0$ & 2 \\
\hline & Medium & $7.0-9.0$ & \\
\hline & Wide & $9.5-12.5$ & \\
\hline \multirow[t]{3}{*}{ E3 } & Narrow & $2.8-4.5$ & 1 \\
\hline & Medium & $4.8-7.8$ & \\
\hline & Wide & $8.0-10.0$ & \\
\hline \multirow[t]{3}{*}{$\mathrm{E} 4$} & Narrow & $2.8-4.5$ & 1 \\
\hline & Medium & $4.8-7.8$ & \\
\hline & Wide & $8.0-10.0$ & \\
\hline \multirow[t]{3}{*}{ E5 } & Narrow & $2.5-6.0$ & 2 \\
\hline & Medium & $7.0-9.0$ & \\
\hline & Wide & $9.5-12.5$ & \\
\hline \multirow[t]{3}{*}{ E6 } & Narrow & $2.8-4.5$ & 1 \\
\hline & Medium & $4.8-7.8$ & \\
\hline & Wide & $8.0-10.0$ & \\
\hline
\end{tabular}

NB: $\mathrm{E}=$ Extraction

Table 2. The parameters and conditions of exhaust method.

\begin{tabular}{ccc}
\hline Parameters & Exhaust method & Modified exhaust method \\
\hline $\mathrm{pH}$ & $4.5-5.0$ & $4.5-5.0$ \\
Concentration & $0.3 \%-2 \%$ & $10 \%$ \\
Time & 20 to 30 minutes & 2 hours \\
Temperature & $40^{\circ} \mathrm{C}$ & $40^{\circ} \mathrm{C}$ \\
Drying & Dry at room temperature & Dry at room temperature
\end{tabular}

Treatment of fibers with Cepreton UN using both exhaust and modified exhaust method

Initially, 2 grams of Cepreton UN were dissolved in $100 \mathrm{ml}$ of water to make a $2 \%$ solution, and then 0.5 grams of extracted dried fibers (E4) were soaked and incubated in a water bath for 30 minutes at $40^{\circ} \mathrm{C}$ (exhaust method, Table 2). Furthermore, 10 grams of chemical was solubilized in $100 \mathrm{ml}$ of water in a beaker to form a $10 \%$ solution, followed by 0.5 grams of dried fiber (E2) soaked in water bath for 2 hours at $40^{\circ} \mathrm{C}$ (modified exhaust method, Table 2). The beaker was covered with a lid to prevent contamination. The $\mathrm{pH}$ was measured by using a pH meter and adjusted using acetic acid at 4.5. Various treatments were per- 
formed in the water bath located in the Department of Biosystems Engineering at University of Manitoba at a $40 \pm 2 \mathrm{rpm}$ speed. The fibers were incubated for 72 hours without any water washing under a $25^{\circ} \mathrm{C} \pm 2{ }^{\circ} \mathrm{C}$ temperature and $33 \% \pm$ $2 \%$ relative humidity $(\mathrm{RH})$. As a result of treatment, the fiber color remained unchanged when we used exhaust method. However, when the modified exhaust method was used, the fibers turned from light greenish to light brownish.

\section{Separation of fibers}

The air-dried fibers were individually separated from each other using a sharp needle after soaking in distilled water for 10 minutes and again air dried in lab (nearly $25^{\circ} \mathrm{C} \pm 2^{\circ} \mathrm{C}$ temperature and $33 \% \pm 2 \% \mathrm{RH}$ ) for 72 hours. Then the separated air-dried fibers were packed in a small, sealed plastic bag and stored at the lab for further investigation. After treatment, 50 fibers were separated and prepared to measure diameter and strength of each stem diameter of a single set. Therefore, a total 150 fibers of each set were selected for fiber diameter measurement and strength testing. Here, from 10\% Cepreton UN treated E2, 150 samples were selected and another 150 samples from $2 \%$ Cepreton UN treated E4 were also considered. To compare and test the hypothesis statistically, data collected from control E2 (150 samples) and E4 (150 samples) were also taken into consideration. For hydrophobicity testing (contact angle measurement), 30 individual isolated fibers were prepared to measure the contact angle of each stem diameter of each set. Therefore, a total of 90 fibers of each set were used for fiber hydrophobicity testing. Here, from 10\% Cepreton UN treated E2, 90 samples and from 2\% Cepreton UN treated E4, another 90 samples were prepared. Control samples collected from E2 (90 samples) and E4 (90 samples) were also taken to compare and test the hypothesis statistically. In the following Table 3, fiber numbers of each set were presented.

\section{Determination of fiber diameter}

The Biquant Image Analyzer was used to measure the diameter of the breaking point of fibers. From each fiber, two (narrowest and widest) diameter readings in $\mu \mathrm{m}$ were taken. The mean of these values indicates the final average diameter of the sample. Since the smallest diameter was used for strength measurement, it is likely that the narrowest part of fiber would break the most and its strength is the general case for strength measurement. A diameter in millimeter

Table 3. Sample numbers to measure diameter, strength and contact angle.

\begin{tabular}{ccccccc}
\hline Stems & $\begin{array}{c}\text { 2\% Cepreton UN } \\
\text { treated E4 } \\
\text { (Group-1) } \\
\text { mm }\end{array}$ & $\begin{array}{c}\text { Fibers for D } \\
\text { and S } \\
\mathbf{n}\end{array}$ & $\begin{array}{c}\text { Fibers } \\
\text { for CA } \\
\mathbf{n}\end{array}$ & $\begin{array}{c}\text { 10\% Cepreton } \\
\text { UN treated E2 } \\
\text { (Group-2) } \\
\text { mm }\end{array}$ & $\begin{array}{c}\text { Fibers for } \\
\text { D and S } \\
\mathbf{n}\end{array}$ & $\begin{array}{c}\text { Fibers for } \\
\text { CA } \\
\mathbf{n}\end{array}$ \\
\hline Narrow & $2.75-4.6$ & 50 & 30 & $2.54-5.98$ & 50 & 30 \\
Medium & $4.75-7.75$ & 50 & 30 & $7.05-8.60$ & 50 & 30 \\
Wide & $7.85-10.0$ & 50 & 30 & $9.45-12.81$ & 50 & 30 \\
Total & & 150 & 90 & & 150 & 90 \\
\hline
\end{tabular}

N.B: $\mathrm{E}=$ Extraction, $\mathrm{n}=$ number of sample, $\mathrm{D}=$ Diameter, $\mathrm{S}=$ Strength, $\mathrm{CA}=$ Contact Angle. 
(mm) was used for the contact angle measurement.

\section{Determination of fiber strength}

Using an Instron Strength Tester, the fiber breaking load was measured. The machine was fitted with a 1 Kilo Newton $(\mathrm{KN})$ load cell and fibers were evaluated at an upper crosshead speed of $2 \mathrm{~mm} / \mathrm{min}$ following the principle of constant rate of extension [18]. The $25.4 \mathrm{~mm}$ sample used to measure the fiber strength was considered as the test standard.

\section{Determination of fiber contact angle (CA)}

The Attention Sigma 700 force Tensiometer measures the dynamic contact angle of a fiber sample by advancing (advancing) and withdrawing (receding) it through a liquid [19]. In this study, the fibers' average diameters were taken from their narrowest and widest parts, and water was used as a liquid to dip the fibers.

\section{Estimation of fiber moisture regain (MR) \%}

By incubating the extracted fibers at different relative humidity (RH) \% controlled by desiccators [20], the moisture uptake of the fibers could be measured. The fiber specimens were first conditioned in an oven at $(100 \pm 3)^{\circ} \mathrm{C}$ for 4 hours, weighed, and then again conditioned at $(100 \pm 3)^{\circ} \mathrm{C}$ for 2 hours and measured weight of the fibers. Another 1 hour was spent repeating the same procedure. Once the equilibrium weight was found for two consecutive measurements, the fibers were incubated in a desiccator conditioned at $11.3 \%$ relative humidity (RH) for 24 hours. The samples were then taken out of the desiccator, measured MR (\%) using the following formula, and then put back in the desiccator for another 24 hours. Once the equilibrium weight was determined in two consecutive measurements, the fibers were again put in the oven for 4 hours at $(100 \pm 3)^{\circ} \mathrm{C}$ to condition the fibers. The same procedure was repeated another 6 times, counting total $7 \mathrm{RH}$ (\%) conditions, to measure the moisture regain of fibers. Table 4 presents the conditions used in the MR (\%) experiment.

MR (\%) of the extracted fibers were calculated using the following equation:

$$
\text { Moisture regain }(\mathrm{MR}) \%=\frac{\text { Weight of moisture in the fiber specimen }}{\text { Weight of oven dried fiber specimen }} \times 100
$$

\section{Effect of $\mathrm{pH}$ on fiber moisture regain (MR) \%}

All the fibers were treated with Cepreton UN at low $\mathrm{pH}$ (4.5). So, it was important to know the effect of individual low $\mathrm{pH}$ on fibers. To test this effect, confirmation test was conducted by estimating the MR (\%). In this experiment, only one type of fibers (wide stem fibers of extraction-4) and company provided

Table 4. Parameter used to estimate moisture regain (MR) \%

\begin{tabular}{|c|c|c|c|c|c|}
\hline \multirow{2}{*}{ RH (\%) } & \multicolumn{2}{|c|}{$\begin{array}{l}\text { Moisture regain weight } \\
\text { at different } \mathrm{RH}(\%)\end{array}$} & \multicolumn{3}{|c|}{$\begin{array}{l}\text { Oven dry weight } \\
\text { at }(100 \pm 3)^{\circ} \mathrm{C}\end{array}$} \\
\hline & 24 hours & 24 hours & 4 hours & 2 hours & 1 hour \\
\hline $11.3 \%, 23.5 \%, 55 \%, 75.5 \%, 84.3 \%, 93.6 \%, 100 \%$ & g & g & g & g & g \\
\hline
\end{tabular}

N.B: $\%=$ Percentage, $g=$ gram, $\mathrm{RH}=$ Relative Humidity. 
exhaust method was used. Here, two variables were used, such as $\mathrm{pH} 4.5$ and 7.0. Here, the $\mathrm{pH}(7.0)$ is general water $\mathrm{pH}$ or neutral $\mathrm{pH}$. This experiment was conducted with two replicates. Table 5 is showing the constant and variable conditions of the confirmation test.

\section{Statistical analysis}

The data were analyzed using the software Microsoft Excel, R 3.5.3, and RStudio for Windows 10 (32/64 bits). To observe the effect of fiber diameter on the fiber properties, the following linear mixed models in RStudio were used where the random effect was stem diameter and fixed effects were narrowest and average diameter (Table 6) [21]. The models were developed using the simple formulas of different parameters. The average length, tenacity, and aspect ratio were analyzed against the narrowest diameter and the contact angle was analyzed against average diameter of fibers. ANOVA was analyzed using one tail $\mathrm{t}$-test performed by Satterthwaite's method.

\section{Results and Discussions}

\section{Effect of Cepreton UN treatment on canola fiber properties (p-values)}

Insignificant $(p>0.05)$ differences between different fiber diameters for average length were found in all treated fibers by ANOVA analysis. Significant $(p<$ 0.05 ) differences for elongation at break, load at break, tensile stress, young's modulus, and aspect ratio were observed. This information showed that fiber

Table 5. Constant and variable conditions of the confirmation test.

\begin{tabular}{|c|c|c|c|}
\hline \multicolumn{4}{|c|}{ Constant conditions } \\
\hline Concentration (Cepreton UN) & Time & Temperature & Fibers (Stem diameter) \\
\hline $2 \%$ & 30 minutes & $40^{\circ} \mathrm{C}$ & E4 (Wide) \\
\hline \multicolumn{4}{|c|}{ Variable conditions } \\
\hline \multicolumn{4}{|c|}{ 1) Fiber incubation in $\mathrm{pH}=7.0$} \\
\hline \multicolumn{4}{|c|}{ 2) Fiber incubation in $\mathrm{pH}=4.5$} \\
\hline \multicolumn{4}{|c|}{ 3) Fiber incubation with $2 \%$ Cepreton $\mathrm{UN} \mathrm{UN} \mathrm{in} \mathrm{pH}=7.0$} \\
\hline \multicolumn{4}{|c|}{ 4) Fiber incubation with $2 \%$ Cepreton $\mathrm{UN} \mathrm{UN}$ in $\mathrm{pH}=4.5$} \\
\hline
\end{tabular}

NB: $\mathrm{E}=$ Extraction

Table 6. Models used in this study to test the hypothesis.

\begin{tabular}{cc}
\hline Formulas & Models \\
\hline Tensile stress $=$ Force/Area & $\begin{array}{c}\text { avelength/tenacity/aspectratio/contact angle } \sim \\
\text { narrowest diameter/avediameter }\end{array}$ \\
Tensile stress $=$ Force/Area & tensile stress $\sim$ load at break $\times$ invarea \\
Young's modulus $=$ Stress/Strain & load at break $\sim$ tensile stress $\times$ invarea \\
Young's modulus $=$ Stress/Strain & elongation at break $\sim$ tensile stress/young's modulus
\end{tabular}

N.B: invarea $=$ inverse area, invtensilestrain $=$ inverse tensile strain. 
diameter had strong effects on elongation at break, load at break, tensile stress, young's modulus, and aspect ratio of treated fibers similar to control samples. However, the influence of fiber diameter on tenacity turned from moderate to strong for treated fibers and the influence was strong for contact angle of $10 \%$ Cepreton UN treated fibers (E2) only because significant $(p<0.05)$ differences were observed for tenacity in all treated fibers and for contact angle in $10 \% \mathrm{Ce}$ preton UN treated E2 fibers only (Table 7).

Effect of Cepreton UN treatment on canola fiber variables (corrgram values)

The corrgram values of Table 8 showed that the fiber diameter was not related to average length, elongation at break, and contact angle. For control and treated E2, load at break and tenacity were positively and moderately correlated to the fiber diameter. For both control and treated samples of E4, the correlation of fiber diameter with load at break and tenacity was not found. On the other hand, tensile stress, young's modulus, and aspect ratio were negatively and

Table 7. Observation of the effects of fiber diameter on the physical and mechanical properties of the fibers ( $p$-values).

\begin{tabular}{|c|c|c|c|c|c|c|c|c|}
\hline \multirow{2}{*}{ Properties } & \multicolumn{4}{|c|}{ Narrowest diameter } & \multicolumn{4}{|c|}{ Average diameter } \\
\hline & E2 & T.E-2 & E4 & T.E-4 & E2 & T.E-2 & E4 & T.E-4 \\
\hline Average length (cm) & 0.4165 & 0.3048 & 0.2751 & 0.5817 & - & - & - & - \\
\hline Elongation at break (\%) & $4.24 \mathrm{e}-07^{\star * *}$ & $7.84 \mathrm{e}-07^{\star * *}$ & $0.004891^{* *}$ & $7.898 \mathrm{e}-07^{\star \star \star}$ & - & - & - & - \\
\hline Load at break $(\mathrm{N})$ & $0.008426^{* * *}$ & $<2 \mathrm{e}-16^{* * *}$ & $0.005887^{* *}$ & $7.581 \mathrm{e}-07^{\star * *}$ & - & - & - & - \\
\hline Tenacity (gf/Tex) & $0.01517^{\star}$ & $0.00015^{\star * *}$ & 0.5734 & $1.132 \mathrm{e}-05^{\star \star \star}$ & - & - & - & - \\
\hline Tensile stress (MPa) & $<2 \mathrm{e}-16^{* * *}$ & $<2 \mathrm{e}-16^{* * *}$ & $<2 \mathrm{e}-16^{* * *}$ & $<2 \mathrm{e}-16^{* * *}$ & - & - & - & - \\
\hline Young's modulus (GPa) & $7.262 \mathrm{e}-14^{* * *}$ & $2.621 \mathrm{e}-11^{\star * *}$ & $7.262 \mathrm{e}-14^{* * *}$ & $2.284 \mathrm{e}-11^{\star * *}$ & - & - & - & - \\
\hline Aspect ratio (L/D) & $<2.2 \mathrm{e}-16^{* * *}$ & $<2.2 \mathrm{e}-16^{\star * *}$ & $5.32 \mathrm{e}-11^{* * *}$ & $4.755 \mathrm{e}-11^{\star * *}$ & - & - & - & - \\
\hline Contact angle $\left({ }^{\circ}\right)$ & - & - & - & - & 0.6485 & $0.003818^{* *}$ & 0.6861 & 0.9309 \\
\hline
\end{tabular}

N.B: Significant codes: $0^{(* * *)} 0.001^{(* *)} 0.01^{(*)} 0.05^{\prime}{ }^{\prime} 0.1^{\prime \prime}{ }^{\prime} 1$, “-“ = Blank spot, E = Extraction, T.E = Treated Extraction.

Table 8. Finding the relationship between the variables of control and treated E2 and E4 using corrgram.

\begin{tabular}{cccccc}
\hline & Properties & $\begin{array}{c}\text { E2 } \\
\text { Corrgram values }\end{array}$ & $\begin{array}{c}\text { Treated E2 } \\
\text { Corrgram values }\end{array}$ & $\begin{array}{c}\text { E4 } \\
\text { Corrgram values }\end{array}$ & $\begin{array}{c}\text { Treated E4 } \\
\text { Corrgram values }\end{array}$ \\
\cline { 2 - 5 } & Average length (cm) & 0.07 & -0.08 & 0.09 & 0.04 \\
Elongation at break (\%) & 0.07 & -0.12 & -0.17 & -0.03 \\
diamer & Contact angle ( $\left.{ }^{\circ}\right)$ & 0.03 & -0.29 & -0.03 & -0.01 \\
& Tensile stress (MPa) & -0.57 & -0.37 & -0.38 & -0.24 \\
& Young's modulus (GPa) & -0.66 & -0.50 & -0.50 & -0.43 \\
& Aspect ratio (L/D) & -0.75 & -0.68 & 0.01 & 0.50 \\
\hline
\end{tabular}

N.B: $\mathrm{E}=$ Extraction 
moderately correlated to fiber diameter in all treated fibers. The results of the corrgram values were nearly consistent with the $p$-values of the present study (Table 8).

Effect of Cepreton UN treatment on canola fiber properties (mean values)

E4 and E2 fibers were treated with Cepreton UN using exhaust method (2\%) and modified exhaust method (10\%), respectively. The highest mean value of narrowest diameter of medium stem fibers of control E2 $(59.91 \mu \mathrm{m})$ and wide stem fibers of control E4 $(53.58 \mu \mathrm{m})$ and also the highest average diameter of medium stem fibers of control E2 $(0.10 \mathrm{~mm})$ and wide stem fibers of control E4 $(0.10 \mathrm{~mm})$ was observed. However, the mean values of narrowest diameter were decreased in both medium stem fibers of treated E2 $(49.98 \mu \mathrm{m})$ and wide stem fibers of treated E4 $(42.25 \mu \mathrm{m})$. The average diameter of medium stem fiber of T.E2 $(0.10 \mathrm{~mm})$ remained unchanged whereas the average diameter of wide stem fiber of T.E4 $(0.11 \mathrm{~mm})$ was increased (Table 9). It is also important to mention that the narrowest diameter of treated fibers was decreased in all cases except narrow treated E4 fibers whereas the average diameter was increased in all treated fibers except medium treated E2 fibers. The variations might be due to the effect of variations in the concentration of Cepreton UN (2\% and $10 \%)$ and incubation time (30 minutes and 2 hours).

Interestingly, comparing to control fibers, the mean values of elongation at break, load at break, tenacity, and contact angle were increased for wide stem fibers of $2 \%$ Cepreton UN treated E4, however, decreased for other stem fibers except contact angle (Table 10 and Table 11) and the mean values were decreased for medium stem fibers of $10 \%$ Cepreton UN treated E2, however, increased for other stem fibers except elongation at break for narrow stem fibers where no change was observed (Table 12 and Table 13). Enhanced elongation at

Table 9. The mean values of narrowest and average diameters of fibers.

\begin{tabular}{ccccccccc}
\hline \multirow{2}{*}{ Stems } & \multicolumn{3}{c}{$\begin{array}{c}\text { Narrowest diameter }(\mu \mathrm{m}) \\
\text { (used for tensile strength measurement) }\end{array}$} & \multicolumn{3}{c}{ (used for contact angle measurement) } \\
\cline { 2 - 10 } & E4 & T.E4 & E2 & T.E2 & E4 & T.E4 & E2 & T.E2 \\
\hline Narrow & $49.28 \pm 1.46$ & $43.82 \pm 1.12$ & $37.82 \pm 0.14$ & $48.58 \pm 0.71$ & $0.09 \pm 0.03$ & $0.11 \pm 0.02$ & $0.09 \pm 0.03$ & $0.10 \pm 0.03$ \\
Medium & $59.91 \pm 1.54$ & $40.83 \pm 0.19$ & $42.64 \pm 1.37$ & $49.98 \pm 0.92$ & $0.09 \pm 0.03$ & $0.11 \pm 0.03$ & $0.10 \pm 0.03$ & $0.10 \pm 0.03$ \\
Wide & $45.18 \pm 1.03$ & $42.25 \pm 0.41$ & $53.58 \pm 1.61$ & $48.58 \pm 0.71$ & $0.10 \pm 0.02$ & $0.11 \pm 0.12$ & $0.08 \pm 0.02$ & $0.09 \pm 0.02$ \\
\hline
\end{tabular}

N.B: Mean \pm standard deviation, $E=$ Extraction, T.E $=$ Treated Extraction, $\mu \mathrm{m}=$ Micrometer.

Table 10. Observation of the effects of stem diameter on the mechanical properties of the E4 \& T.E4 fibers (mean-values).

\begin{tabular}{|c|c|c|c|c|c|c|c|c|}
\hline \multirow{2}{*}{ Stems } & \multicolumn{2}{|c|}{ Average length $(\mathrm{cm})$} & \multicolumn{2}{|c|}{ Elongation at break (\%) } & \multicolumn{2}{|c|}{ Load at break (N) } & \multicolumn{2}{|c|}{ Tenacity (gf/tex) } \\
\hline & E4 & T.E4 & E4 & T.E4 & E4 & T.E4 & E4 & T.E4 \\
\hline Medium & $5.80 \pm 1.60$ & $5.72 \pm 1.68$ & $1.72 \pm 0.08$ & $1.49 \pm 0.07$ & $0.56 \pm 0.06$ & $0.55 \pm 0.06$ & $0.56 \pm 0.06$ & $0.55 \pm 0.06$ \\
\hline Wide & $5.93 \pm 2.01$ & $5.38 \pm 1.69$ & $2.16 \pm 0.08$ & $2.37 \pm 0.12$ & $0.79 \pm 0.02$ & $0.96 \pm 0.10$ & $0.79 \pm 0.02$ & $0.98 \pm 0.10$ \\
\hline
\end{tabular}

N.B: Mean \pm standard deviation, $\mathrm{E}=$ Extraction, T.E $=$ Treated Extraction. 
Table 11. Observation of the effects of stem diameter on the mechanical properties of the E4 \& T.E4 fibers (mean-values)

\begin{tabular}{ccccccccc}
\hline \multirow{2}{*}{ Stems } & \multicolumn{2}{c}{ Tensile stress $(\mathrm{MPa})$} & \multicolumn{2}{c}{ Young's modulus $(\mathrm{GPa})$} & \multicolumn{2}{c}{ Aspect ratio (L/D) } & \multicolumn{2}{c}{ Contact angle $\left(^{\circ}\right)$} \\
\cline { 2 - 9 } & E4 & T.E4 & E4 & T.E4 & E4 & T.E4 & E4 & T.E4 \\
\hline Narrow & $502.664 \pm 56.85$ & $249.01 \pm 30.03$ & $54.76 \pm 3.72$ & $39.94 \pm 3.13$ & $14,979.31 \pm 118.56$ & $12,405.5 \pm 345.59$ & $112.1 \pm 6.43$ & $126.25 \pm 17.53$ \\
Medium & $446.90 \pm 77.62$ & $385.34 \pm 33.99$ & $55.50 \pm 5.20$ & $54.61 \pm 2.89$ & $14,056.47 \pm 114.54$ & $13,841.52 \pm 274.23$ & $122.45 \pm 12.38$ & $127.53 \pm 15.24$ \\
Wide & $237.16 \pm 50.13$ & $217.86 \pm 16.16$ & $40.45 \pm 3.65$ & $34.57 \pm 1.82$ & $13119.41 \pm 451.99$ & $12,613.54 \pm 345.22$ & $128.72 \pm 16.43$ & $130.39 \pm 16.72$ \\
\hline
\end{tabular}

N.B: Mean \pm standard deviation, $\mathrm{E}=$ Extraction, T.E $=$ Treated Extraction.

Table 12. Observation of the effects of stem diameter on the physical and mechanical properties of the E2 \& T.E2 fibers (mean-values).

\begin{tabular}{ccccccccc}
\hline \multirow{2}{*}{ Stems } & \multicolumn{2}{c}{ Average length $(\mathrm{cm})$} & \multicolumn{2}{c}{ Elongation at break $(\%)$} & \multicolumn{2}{c}{ Load at break $(\mathrm{N})$} & \multicolumn{2}{c}{ Tenacity $(\mathrm{gf} / \mathrm{tex})$} \\
\cline { 2 - 9 } & E2 & T.E2 & E2 & T.E2 & E2 & T.E2 & E2 & T.E2 \\
\hline Narrow & $5.08 \pm 0.96$ & $5.92 \pm 1.40$ & $1.56 \pm 0.12$ & $1.56 \pm 0.11$ & $0.38 \pm 0.02$ & $0.44 \pm 0.05$ & $0.40 \pm 0.02$ & $0.44 \pm 0.05$ \\
Medium & $5.02 \pm 1.17$ & $5.84 \pm 1.46$ & $1.80 \pm 0.11$ & $1.64 \pm 0.14$ & $0.49 \pm 0.05$ & $0.45 \pm 0.05$ & $0.50 \pm 0.06$ & $0.46 \pm 0.05$ \\
Wide & $4.78 \pm 1.12$ & $5.66 \pm 1.36$ & $1.64 \pm 0.10$ & $1.74 \pm 0.05$ & $0.40 \pm 0.04$ & $0.61 \pm 0.03$ & $0.40 \pm 0.04$ & $0.62 \pm 0.03$ \\
\hline
\end{tabular}

N.B: Mean \pm standard deviation, $\mathrm{E}=$ Extraction, T.E $=$ Treated Extraction.

Table 13. Observation of the effects of stem diameter on the physical and mechanical properties of the E2 \& T.E2 fibers (mean-values).

\begin{tabular}{ccccccccc}
\hline \multirow{2}{*}{ Stems } & \multicolumn{2}{c}{ Tensile stress $(\mathrm{MPa})$} & \multicolumn{2}{c}{ Young's modulus (GPa) } & \multicolumn{2}{c}{ Aspect ratio (L/D) } & \multicolumn{2}{c}{ Contact angle $\left(\left(^{\circ}\right)\right.$} \\
\cline { 2 - 9 } & E2 & T.E2 & E2 & T.E2 & E2 & T.E2 & E2 & T.E2 \\
\hline Narrow & $228.31 \pm 28.41$ & $238.39 \pm 23.81$ & $26.73 \pm 2.40$ & $27.88 \pm 1.77$ & $10,840.97 \pm 412.09$ & $11,874.46 \pm 391.25$ & $113.28 \pm 7.91$ & $128.86 \pm 16.43$ \\
Medium & $192.38 \pm 22.28$ & $226.80 \pm 26.01$ & $20.25 \pm 3.13$ & $24.50 \pm 3.06$ & $8606.27 \pm 256.32$ & $12,095.6 \pm 389.27$ & $127.78 \pm 14.33$ & $119.07 \pm 14.85$ \\
Wide & $196 \pm 30.47$ & $340.77 \pm 20.61$ & $22.56 \pm 2.76$ & $27.35 \pm 1.44$ & $9289.10 \pm 382.59$ & $12,210.25 \pm 423.95$ & $118.35 \pm 12.85$ & $121.58 \pm 11.76$ \\
\hline
\end{tabular}

N.B: Mean \pm standard deviation, $\mathrm{E}=$ Extraction, T.E $=$ Treated Extraction.

break increases the fiber relative flexibility [22]. In a fabric, with the enhanced breaking load, the tightness of the yarns reduced and the flexibility of the yarn increased [23]. The high tenacity yarn is used in fabric industries [24] [25]. Fiber with poor absorbency and wettability and high hydrophobicity help to maintain its long lasting quality at different atmospheric conditions [19] [26]. Therefore, $2 \%$ Cepreton UN treated E4 wide stem fibers were less stiff and 10\% Cepreton UN treated E2 medium stem fibers were stiffer than their respective control fibers.

On the contrary, the mean values of tensile stress, young's modulus, and aspect ratio were found to be decreased for fibers of $2 \%$ Cepreton UN treated E4 (Table 11) and increased fibers of $10 \%$ Cepreton UN treated E2 (Table 13). In general, the higher fiber aspect ratio makes the fibers relatively less flexible and stiffer increasing the tensile stress and young's modulus [27]. Moreover, flexible material can change its shape due to its low young's modulus [28] [29]. Therefore, 2\% Cepreton UN treated E4 fibers were less stiff and 10\% Cepreton UN treated E2 fibers were stiffer than the control fibers. Variations were found in elongation at break, load at break, tenacity, and contact angle for narrow and 
medium stem fibers of 2\% Cepreton UN treated E4 fibers and narrow and wide stem fibers of $10 \%$ Cepreton UN treated E2 fibers. Moreover, with gradual decrease in fiber diameter, the tensile stress and young's modulus of natural fibers increases [30]. However, in this study, the narrowest diameter of treated fibers was mostly decreased with decreased tensile stress and young's modulus. These unusual properties might be due to the effect of Cepreton UN treatment on the fiber intrinsic properties. Hence, our null hypothesis was accepted for the wide stem 2\% Cepreton UN treated E4 fibers and rejected for the medium stem $10 \%$ Cepreton UN treated E2 fibers. For average length, the mean values were decreased when the fibers were treated with $2 \%$ Cepreton UN (Table 10) and increased when the treatment was 10\% Cepreton UN (Table 12) from their respective control fibers. The differences between control and treated fibers and also $2 \%$ and $10 \%$ treated fibers were found statistically significant $(p<0.05)$ when a linear model was used.

Moreover, all those properties of treated canola fibers comparing with the values of cotton and jute shows that the mean values of $2 \%$ Cepreton UN treated wide stem fibers of E4 were close to cotton and jute and the mean values of $10 \%$ Cepreton UN treated medium stem fibers of E2 were far from cotton and jute (Table 14) and hence, the physical and mechanical properties of $2 \%$ Cepreton $\mathrm{UN}$ treated wide stem fibers of E4 were relatively more close to cotton and jute than the control E4. On the contrary, the physical and mechanical properties of $10 \%$ Cepreton UN treated medium stem fibers of E2 were far from cotton and jute than the control E2. Hence, exhaust method acts similarly on lignocellulosic canola bast fibers and cellulosic seed fibers.

In this study, $2 \%$ Cepreton UN was used as company provided exhaust method whereas $10 \%$ Cepreton UN was used as modified exhaust method. Considering all the above properties, it was revealed that $2 \%$ Cepreton UN or exhaust method was useful to make the fiber flexible for textile applications where more flexible fibers are used [40]. On the other hand, 10\% Cepreton UN or modified exhaust method was useful for composite productions where less flexible fibers are used [41]. Xie et al. revealed that the fiber-matrix interfacial interactions can be induced through formation of strong chemical bonding by silane coupling agents and therefore, results in considerable improvement in the mechanical performance of composites [7]. In this study, $10 \%$ Cepreton UN with low $\mathrm{pH}$ functioned in the similar way like silane coupling agents. The variations between the two methods were the concentrations of Cepreton UN and the incubation

Table 14. Physical and mechanical properties of cotton. Cotton: [31] [32] [33] [34] and Jute: [3] [31] [35] [36] [37] [38] [39].

\begin{tabular}{lcccccccccc}
\hline Fibers & $\begin{array}{c}\text { Diameter } \\
(\mu \mathrm{m})\end{array}$ & $\begin{array}{c}\text { Length } \\
(\mathrm{cm})\end{array}$ & $\begin{array}{c}\text { Moiture } \\
\text { Regain } \\
(\%)\end{array}$ & $\begin{array}{c}\text { Contact angle } \\
\left({ }^{\circ}\right)\end{array}$ & $\begin{array}{c}\text { Elongation } \\
\text { at break } \\
(\%)\end{array}$ & $\begin{array}{c}\text { Load at } \\
\text { break } \\
(\mathrm{N})\end{array}$ & $\begin{array}{c}\text { Tenacity } \\
(\mathrm{gf} / \mathrm{tex})\end{array}$ & $\begin{array}{c}\text { Tensile } \\
\text { stress } \\
(\mathrm{MPa})\end{array}$ & $\begin{array}{c}\text { Young's } \\
\text { modulus } \\
(\mathrm{GPa})\end{array}$ & $\begin{array}{c}\text { Aspect } \\
\text { ratio } \\
(\mathrm{L} / \mathrm{D})\end{array}$ \\
\hline Cotton & $14-21$ & $1.5-5.6$ & 8.5 & $\begin{array}{c}\sim 0 \text { (control) } \\
156.3 \text { (treated) }\end{array}$ & $3-12$ & $1.63-1.97$ & $1.7-6.3$ & $287-597$ & 4.8 & 1400 \\
Jute & $12-18$ & $100-400$ & $10-12$ & $36-42$ & $1.69-1.83$ & 31.63 & $26.5-51.2$ & $300-700$ & $20-50$ & 150 \\
\hline
\end{tabular}


time. Modified exhaust method was not statistically optimized, hence, this method cannot be recommended as standards for large scale utilization for canola fiber.

Effect of Cepreton UN treatment on canola fiber moisture regain (MR) \%

An upward trend of $\mathrm{MR}(\%)$ was observed for $11.3 \%, 23.5 \%, 55 \%, 75.5 \%$, $84.3 \%, 93.6 \%$ RH. A sudden decrease in MR (\%) was found at $100 \% \mathrm{RH}$ for control samples. However, for both $2 \%$ and $10 \%$ treated samples, at $100 \% \mathrm{RH}$, an increasing trend in MR (\%) was observed (Table 15 and Table 16). At saturated condition, fiber moisture regain capacity might be increased due to fiber surface modification with Cepreton UN. The pattern was similar for all wide, medium, and narrow stem fibers of control and treated E2 and E4 which revealed that stem diameter did not have any effect on MR (\%) of treated fibers. Here, our null hypothesis was again rejected. The MR (\%) of canola fibers changes with the change of $\mathrm{RH}$ (\%) which is also true for other natural fibers [42] [43] even after

Table 15. MR (\%) of fibers in different RH (\%) for E4 and treated E4.

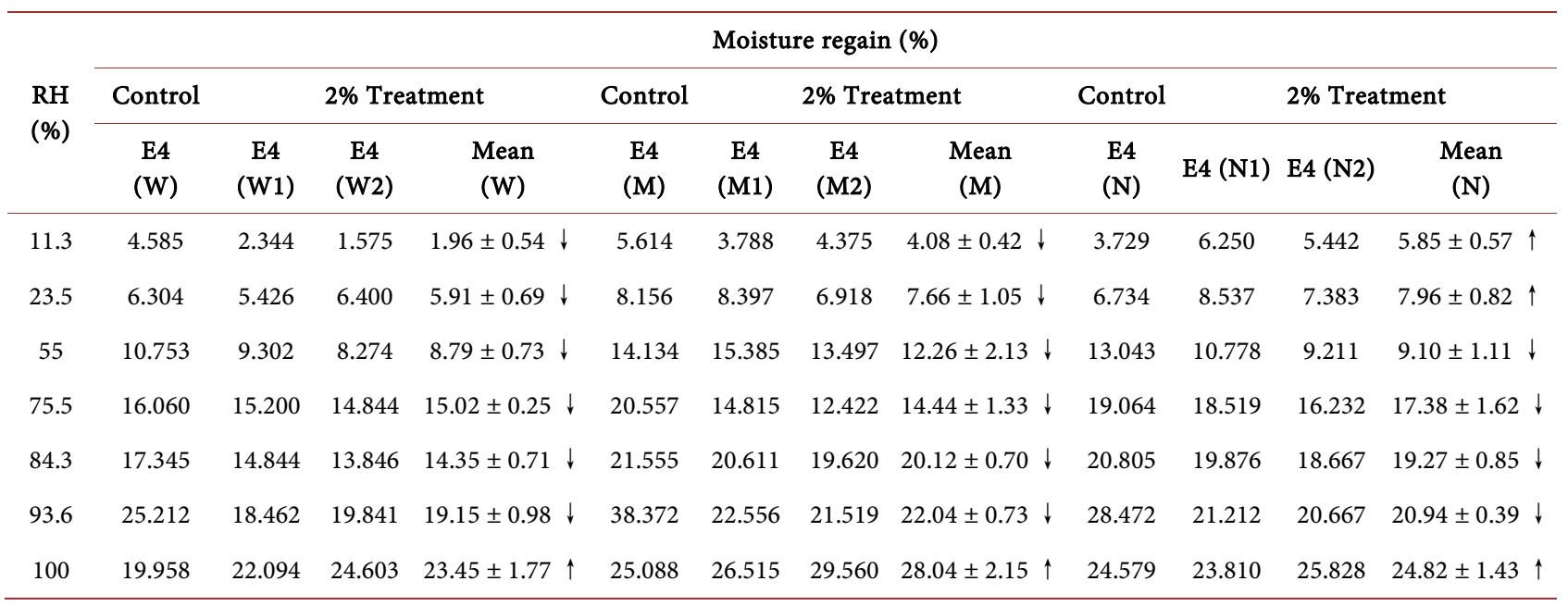

N.B: Mean \pm standard deviation, $\mathrm{E}=$ Extraction, $\mathrm{W}=$ Wide, $\mathrm{M}=$ Medium, $\mathrm{N}=$ Narrow, $\mathrm{MR}=$ Moisture regain, $\mathrm{RH}=\mathrm{Relative} \mathrm{Humidity}$.

Table 16. MR (\%) of fibers in different RH (\%) for E2 and treated E2.

\begin{tabular}{|c|c|c|c|c|c|c|c|c|c|c|c|c|c|c|c|}
\hline \multirow[b]{2}{*}{ RH (\%) } & \multicolumn{15}{|c|}{ Moisture regain (\%) } \\
\hline & \multicolumn{2}{|l|}{ Control } & \multicolumn{2}{|c|}{$10 \%$ Treatment } & \multicolumn{3}{|c|}{ Control } & \multicolumn{2}{|c|}{$10 \%$ Treatment } & \multicolumn{3}{|c|}{ Control } & \multicolumn{3}{|c|}{$10 \%$ Treatment } \\
\hline 11.3 & 4.607 & 5.263 & 5.650 & $5.46 \pm 0.27$ & $\uparrow$ & 2.116 & 4.739 & 4.636 & $4.69 \pm 0.07$ & $\uparrow$ & 4.088 & 4.908 & 3.483 & $4.20 \pm 1.01$ & $\uparrow$ \\
\hline 23.5 & 5.482 & 6.034 & 6.180 & $6.11 \pm 0.10$ & $\uparrow$ & 6.720 & 7.109 & 9.211 & $8.16 \pm 1.49$ & $\uparrow$ & 5.938 & 7.407 & 6.533 & $6.97 \pm 0.62$ & $\uparrow$ \\
\hline 55 & 10.816 & 9.787 & 12.222 & $11.01 \pm 1.72$ & $\uparrow$ & 12.807 & 11.321 & 9.554 & $10.44 \pm 1.25$ & $\downarrow$ & 11.111 & 9.697 & 9.950 & $9.82 \pm 0.18$ & $\downarrow$ \\
\hline 75.5 & 16.920 & 15.652 & 16.292 & $15.97 \pm 0.45$ & $\downarrow$ & 18.182 & 15.421 & 13.548 & $14.48 \pm 1.32$ & $\downarrow$ & 18.769 & 15.854 & 15.000 & $15.43 \pm 0.60$ & $\downarrow$ \\
\hline 84.3 & 19.265 & 18.777 & 18.857 & $18.82 \pm 0.06$ & $\downarrow$ & 19.891 & 21.226 & 19.231 & $20.23 \pm 1.41$ & $\uparrow$ & 24.149 & 21.875 & 22.000 & $21.94 \pm 0.09$ & $\downarrow$ \\
\hline 93.6 & 29.490 & 21.983 & 20.109 & $21.05 \pm 1.33$ & $\downarrow$ & 33.607 & 29.858 & 24.837 & $27.35 \pm 3.55$ & $\downarrow$ & 33.453 & 24.691 & 26.000 & $25.45 \pm 0.93$ & $\downarrow$ \\
\hline 100 & 26.426 & 27.632 & 26.923 & $27.28 \pm 0.50$ & $\uparrow$ & 30.081 & 34.762 & 28.387 & $31.58 \pm 4.51$ & $\uparrow$ & 31.826 & 27.273 & 28.500 & $27.89 \pm 0.87$ & $\downarrow$ \\
\hline
\end{tabular}

N.B: Mean \pm standard deviation, $\mathrm{E}=$ Extraction, $\mathrm{W}=$ Wide, $\mathrm{M}=$ Medium, $\mathrm{N}=$ Narrow, $\mathrm{MR}=$ Moisture regain, $\mathrm{RH}=\mathrm{Relative} \mathrm{Humidity}$. 
$2 \%$ and $10 \%$ Cepreton UN treatment. Here, the treated mean value was compared with the actual control value.

When the fibers (E4) were treated with $2 \%$ Cepreton UN, the mean values of MR (\%) in almost all RH (\%) were found mostly decreased than the control fibers (E4). But when the fibers (E2) were treated with $10 \%$ Cepreton UN, the mean values of MR (\%) in most of the $\mathrm{RH}$ (\%) were found increased or the variation was less than the control fibers (E2) (Table 15 and Table 16). This result is consistent with our previously observed results for E4 (Table 10 and Table 11) and E2 (Table 12 and Table 13). When a linear model was used, the MR (\%) differences between control and treated fibers and also $2 \%$ and $10 \%$ treated fibers were found statistically significant $(p<0.05)$. This result suggests that high concentration $10 \%$ Cepreton UN treatment for a long time (2 hours) made the fibers regain more moisture (\%). On the other hand, $2 \%$ Cepreton UN made the fibers regain less moisture (\%). The cotton and jute MR (\%) are also very low, only $8.5 \%$ and $10 \%-12 \%$, respectively which showed that quality of the fibers was relatively near to cotton and jute when it was treated with $2 \%$ Cepreton UN. Moreover, if the fibers gain and lose less moisture at different $\mathrm{RH}(\%)$, the relative performance of fibers would remain intact for a long time [44]. Hence, using high concentration of softener for a long time did not make the fibers regain less moisture (\%). All in all, the fibers with exhaust method treatment gained less moisture content than the modified exhaust method treatment. Therefore, $2 \%$ Cepreton UN or exhaust method was more useful to make the fiber maintain its original quality for a long time than $10 \%$ Cepreton UN or modified exhaust method. Water-repelling agents can reduce moisture absorption and subsequent swelling of natural fibers [7] where both methods functioned like water-repelling agents.

\section{Effect of $\mathrm{pH}$ on fiber moisture regain (MR) \%}

To ensure the effect of Cepreton UN in the external properties of fibers, it was necessary to confirm the non-involvement of the other external factors, such as $\mathrm{pH}$, where we did a confirmation test using two $\mathrm{pH}$ (4.5 and 7.0) following exhaust method. At pH 4.5, an increasing trend was observed in MR (\%) for control fibers in $11.3 \%, 23.5 \%, 55 \%, 75.5 \%, 84.3 \%, 93.6 \%$ and $100 \% \mathrm{RH}$ conditions (Figure 1). An increasing trend was also observed in MR (\%) for 2\% Cepreton UN treated fibers at neutral $\mathrm{pH}$ in $11.3 \%, 23.5 \%, 55 \%, 75.5 \%, 84.3 \%, 93.6 \%$ and $100 \% \mathrm{RH}$ conditions (Figure 2). This observed pattern was almost as similar as 2\% Cepreton treatment at low pH (4.5) (exhaust method). At neutral pH 7.0, the increasing trend of $\mathrm{MR}(\%)$ was observed for $11.3 \%, 23.5 \%, 75.5 \%, 84.3 \%$, and 93.6\% RH. On the other hand, a sudden drop in MR (\%) was found at $100 \% \mathrm{RH}$ for control samples at neutral $\mathrm{pH}$ (Figure 2).

The MR (\%) was decreased in almost all conditions except control fibers at neutral $\mathrm{pH}$ 7.0. This result showed that individually $\mathrm{pH} 4.5$ and individually $2 \%$ Cepreton UN and combination of both (2\% Cepreton UN and pH 4.5) had effect on MR (\%) of canola fibers. It also found that the individual effect of $\mathrm{pH} 4.5$ 


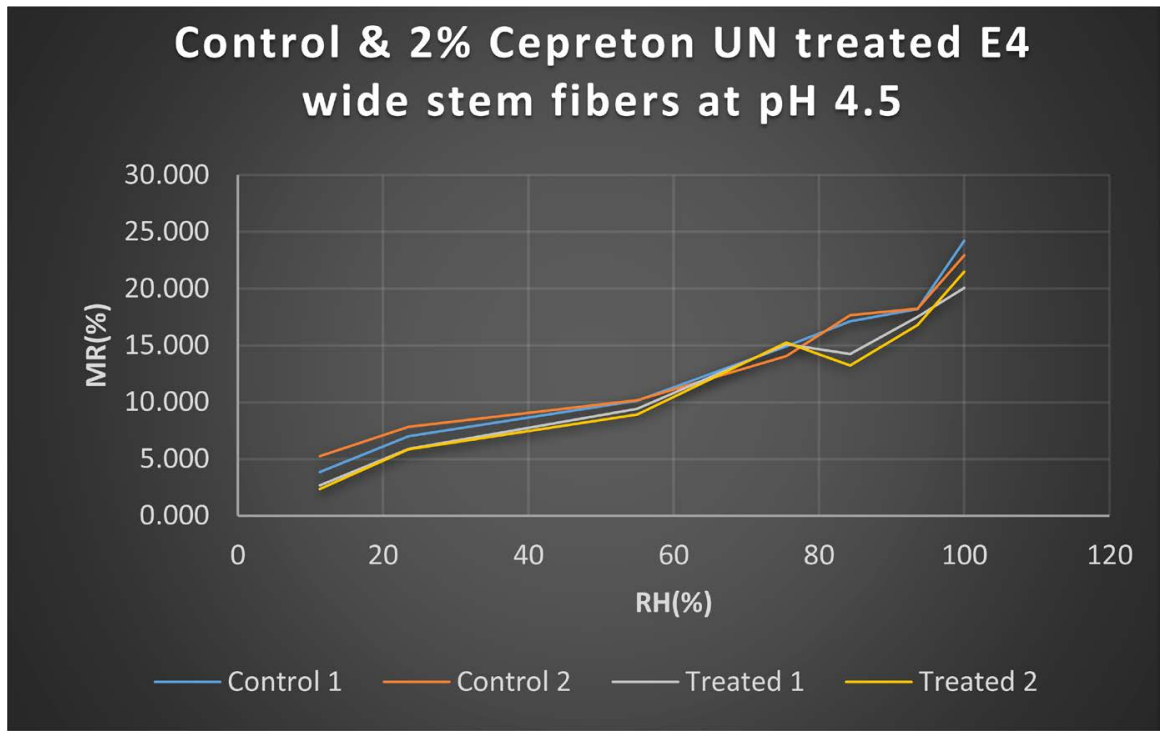

Figure 1. Effect of $\mathrm{pH} 4.5$ of control and treated fibers on moisture regain (\%). The MR (\%) increased in all cases (control and 2\% Cepreton UN treated fibers at $\mathrm{pH} 4.5$ ) at $100 \%$ RH condition.

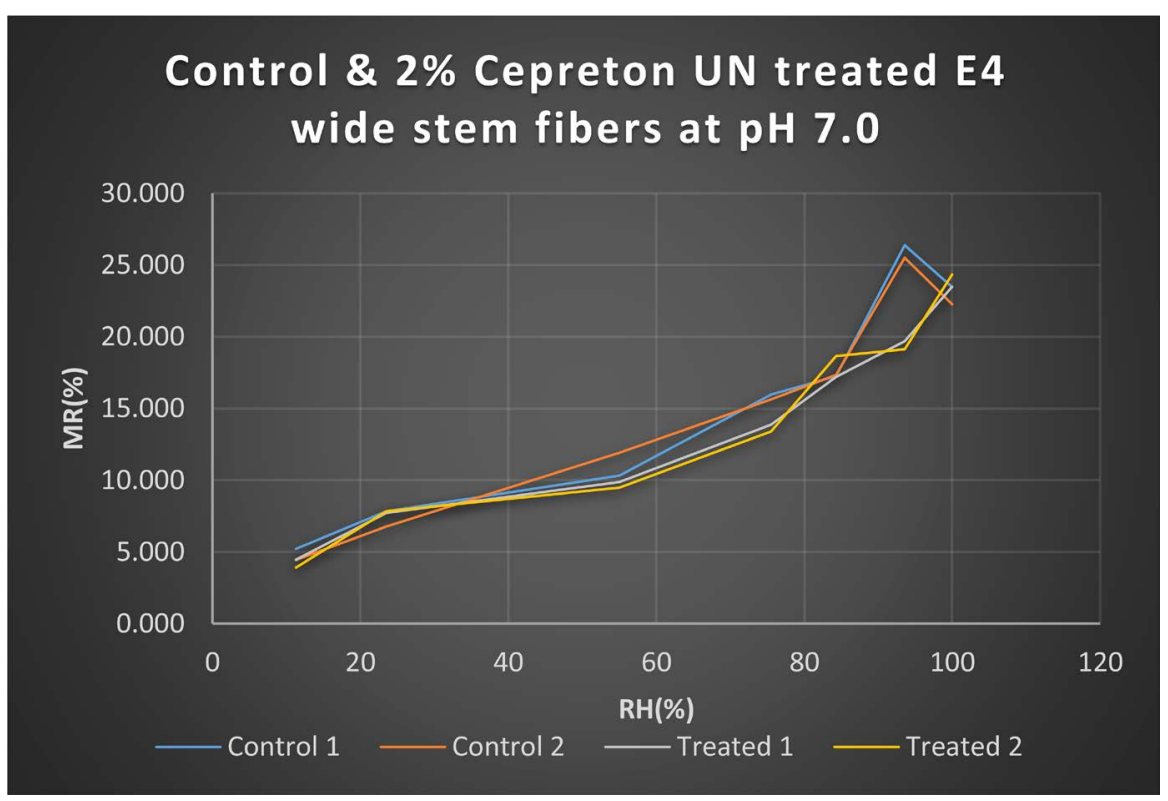

Figure 2. Effect of pH 7.0 of control and treated fibers on moisture regain (\%). The MR (\%) increased in $2 \%$ Cepreton UN treated and decreased in control fibers at $\mathrm{pH} 7.0$ at $100 \% \mathrm{RH}$ condition.

or $2 \%$ Cepreton UN at neutral $\mathrm{pH}(7.0)$ is nearly as similar on MR (\%) as the combination ( $\mathrm{pH} 4.5$ and $2 \%$ Cepreton UN). When a linear model was used, the MR (\%) differences between treated at pH 4.5 and control at $\mathrm{pH} 4.5$, control at $\mathrm{pH}$ at 7.0 and treated at $\mathrm{pH} 7.0$ fibers were found statistically significant $(p<$ 0.05). Therefore, only decreasing the $\mathrm{pH}$ of water at 4.5 would make the fibers better to touch. On the contrary, Li et al. revealed that alkali can improve the mechanical properties of natural fibers significantly by removing some weak 
components like hemicelluloses and lignin from the fiber structure and also by modifying their crystalline structure [45] which is consistent with our current findings. Besides commercial fabric softeners, emulsion stabilizers, acids or bases to maintain an optimal $\mathrm{pH}$ for absorption, fragrance enhancers, and coloring agents are also considered as softeners [14]. Therefore, all in all, the fibers with low $\mathrm{pH}$ (4.5) or $2 \%$ Cepreton UN treatment at neutral $\mathrm{pH}$ (7.0) would gain less moisture content maintaining their originality for extended period at different atmospheric conditions just as the combination (2\% Cepreton UN and $\mathrm{pH} 4.5$ ).

\section{Conclusions}

Both 2\% (exhaust method) and 10\% Cepreton UN (modified exhaust method) treated fiber diameter had effects on the mechanical and physical properties, such as elongation and load at break, tenacity, contact angle, tensile stress, young's modulus, and aspect ratio. On the other hand, fiber diameter had no effect on some physical properties, such as average length for both $2 \%$ and $10 \%$ Cepreton UN treated fibers. Fiber diameter was positively correlated to tenacity and load at break whereas fiber diameter was negatively correlated to tensile stress, young's modulus and aspect ratio. The mean values of elongation at break (\%), load at break, tenacity, and contact angle (hydrophobicity) were found to be relatively higher for $2 \%$ Cepreton UN treated wide stem fibers and the mean values of tensile stress, young's modulus, and aspect ratio were found to be relatively lower for $2 \%$ Cepreton UN treated wide stem fibers than the wide stem control fibers. Those values were found to be closed to that of cotton and jute showing relatively close properties of cotton and jute. All together those properties made $2 \%$ Cepreton UN treated fibers relatively less stiff than control fibers. On the other hand, the opposite effects were observed in 10\% Cepreton UN treated medium stem fibers. The properties were found to be far from that of cotton and jute showing properties that were relatively far from cotton and jute. All together those properties made 10\% Cepreton UN treated medium stem fibers relatively stiffer than control medium stem fibers. Therefor 2\% Cepreton UN treatment (exhaust method) was better than 10\% Cepreton UN treatment (modified exhaust method) in increasing the lignocellulosic canola bast fiber relative flexibility and holding fiber originality for a long time. So, increasing the concentration of softener and treatment time would not make the fiber softer and better to touch.

An upward trend of MR (\%) was observed at different RH (\%) except at 100\% RH of control fibers. However, in both exhaust method and modified exhaust method treated fibers, the MR (\%) was found to increase at $100 \% \mathrm{RH}$. When the fibers were treated with the exhaust method, the mean values of MR (\%) at different $\mathrm{RH}$ (\%) were found mostly decreased than the control fibers which showed that those fibers could gain less moisture than their respective control fibers. On the contrary, when the fibers were treated with modified exhaust method, the mean values of MR (\%) at different RH (\%) were found to be mostly 
increased or the variation was less than the control fibers which showed that those fibers could gain more moisture than their respective control fibers. Therefore, exhaust method was more useful to make fiber to maintain its original quality for long at different $\mathrm{RH}(\%)$ than the modified exhaust method.

Individually low $\mathrm{pH}$ (4.5) and 2\% Cepreton treatment at neutral $\mathrm{pH}(7.0) \mathrm{had}$ nearly similar effect as $2 \%$ Cepreton at low $\mathrm{pH}(4.5)$ on MR (\%) of canola fibers. Hence, to make fibers better to touch and retaining fiber original quality, low $\mathrm{pH}$ treatment would be a great alternative of any commercial softener. As $2 \% \mathrm{Ce}$ preton UN at neutral $\mathrm{pH}$ (7.0) also had almost similar effect as low $\mathrm{pH}$ (4.5) on MR (\%), therefore, using $2 \%$ Cepreton UN at neutral $\mathrm{pH}$ (7.0) alone was also enough to make canola fibers better to touch and maintaining fiber original quality for long at different atmospheres. The difference between the exhaust method and the modified exhaust method was the concentration of Cepreton UN ( $2 \%$ and $10 \%)$ and the treatment time ( 30 minutes and 2 hours). It would be interesting to investigate the physical and mechanical properties of fibers in 10\% Cepreton UN for 30 minutes treatment as well. The other treatments could be using low $\mathrm{pH}$ (4.5) or $2 \%$ Cepreton UN at neutral $\mathrm{pH}$ (7.0).

\section{Acknowledgements}

We are thankful to the personnel of the Textile Laboratory of the Department of Biosystems Engineering, University of Manitoba for providing the necessary logistic support and training.

\section{Conflicts of Interest}

The authors declare no conflicts of interest regarding the publication of this paper.

\section{References}

[1] Hatch, K.L. (1993) Fiber Properties and Identification. In: Textile Science, West Publishing, Saint Paul, 108-127.

[2] Smulders, E., von Rybinski, W., Sung, E., Rähse, W., Steber, J., Wiebel, F. and Nordskog, A. (2007) Laundry Detergents. In: Ullmann's Encyclopedia of Industrial Chemistry, Wiley, Hoboken, 5-10. https://doi.org/10.1002/14356007.a08_315.pub2

[3] Mia, R., Ahmed, B. and Mojumdar, J. (2017) Woolenization of Jute Fibre. European Scientific Journal, 13, 314-326. https://doi.org/10.19044/esj.2017.v13n30p314

[4] Anwar, A. (2007) Information on Jute, Kenaf, Roselle Hemp and Natural/Bast Fiber Textile Products by GFTCL. http://exporter-of-jute-products.blogspot.com

[5] Ku, H., Wang, H., Pattarachaiyakoop, N. and Trada, M. (2011) A Review on the Tensile Properties of Natural Fiber Reinforced Polymer Composites. Composites Part B, Engineering, 42, 856-873. https://doi.org/10.1016/j.compositesb.2011.01.010

[6] Shahidi, S., Ghoranneviss, M. and Wiener, J. (2015) Improving Synthetic and Natural Dyeability of Polyester Fabrics by Dielectric Barrier Discharge. Journal of Plastic Film \& Sheeting, 31, 286-308. https://doi.org/10.1177/8756087914567013

[7] Xie, Y., Hill, C., Xiao, Z., Militz, H. and Mai, C. (2010) Silane Coupling Agents Used for Natural Fiber/Polymer Composites: A Review. Composites Part A: Applied Science 
and Manufacturing, 41, 806-819.

https://doi.org/10.1016/j.compositesa.2010.03.005

[8] Pommet, M., Juntaro, J., Heng, J.Y.Y., Mantalaris, A., Lee, A.F., Wilson, K., Kalinka, G., Shaffer, M.S.P. and Bismarck, A. (2008) Surface Modification of Natural Fibers Using Bacteria: Depositing Bacterial Cellulose onto Natural Fibers to Create Hierarchical Fiber Reinforced Nanocomposites. Biomacromolecules, 9, 1643-1651. https://doi.org/10.1021/bm800169g

[9] Needles, H.L. (1986) Textile Fibers, Dyes, Finishes, and Processes: A Concise Guide. Noyes Publications, Park Ridge.

[10] Tanushree and Chanana, B. (2016) Characterization and Mechanical Properties of Bast Fibre. International Journal of Home Science, 2, 291-295.

[11] Kiaei, M., Mahdavi, S., Kialashaki, A., Nemati, M., Samariha, A. and Saghafi, A. (2014) Chemical Composition and Morphological Properties of Canola Plant and Its Potential Application in Pulp and Paper Industry. Cellulose Chemistry and Technology, 48, 105-110.

[12] Kozasowski, R.M., Mackiewicz-Talarczyk, M. and Allam, A.M. (2012) Bast Fibres: Flax. In: Kozłowski, R.M., Ed., Handbook of Natural Fibres. Types, Properties and Factors Affecting Breeding and Cultivation, Vol. 1, Woodhead Publishing, Sawston, 56-113. https://doi.org/10.1533/9780857095503.1.56

[13] Macmillan, C.P. and Birke, H. (2016) Lignin Deposition in Cotton Cells? Where Is the Lignin? Journal of Plant Biochemistry \& Physiology, 1, 2-5. https://doi.org/10.4172/2329-9029.1000e106

[14] Schindler, W.D. and Hauser, P.J. (2004) Chemical Finishing of Textiles (Woodhead Publishing Series in Textiles). Woodhead Publishing Limited, Sawston, 1-213. https://doi.org/10.1201/9781439823477

[15] Igarashi, T. and Nakamura, K. (2018) Mechanism of Softening Effect of Fabric Softener. Journal of Materials Science Research, 8, 35. https://doi.org/10.5539/jmsr.v8n1p35

[16] Achroma Life Enhanced (2020) Touch and Feel Effects. https://www.archroma.com/the-archroma-way-to-a-sustainable-world

[17] Parvin, A. (2021) The Effect of Stem Diameter on the Brassica napus (Type: Canola) (Cultivar: HYHEAR 3) Fiber Quality. Master's Thesis, Department of Biosystems Engineering, University of Manitoba, Winnipeg.

[18] Collier, B.J. and Epps, H.H. (1999) Textile Testing and Analysis. 7th Edition, Prentice Hall, Hoboken, 374.

[19] Yuan, Y. and Lee, T.R. (2013) Contact Angle and Wetting Properties. In: Surface Science Techniques, Vol. 51, Springer, Berlin, 3-34.

https://doi.org/10.1007/978-3-642-34243-1_1

[20] ASTM D5229 (2004) Standard Test Method for Moisture Absorption Properties and Equilibrium Conditioning of Polymer Matrix Composite Material. ASTM International, West Conshohocken. http://file.yizimg.com/175706/2014021816594640.pdf

[21] Bates, D., Mächler, M., Bolker, B.M. and Walker, S.C. (2015) Fitting Linear Mixed-Effects Models Using lme4. Journal of Statistical Software, 67, 1-48. https://doi.org/10.18637/jss.v067.i01

[22] Petroudy, S.R. (2017) Physical and Mechanical Properties of Natural Fibers. In: Fan, M.Z. and Fu, F., Eds., Advanced High Strength Natural Fibre Composites in Construction, Woodhead Publishing, Sawston, 59-83.

https://doi.org/10.1016/B978-0-08-100411-1.00003-0 
[23] Eltahan, E. (2018) Structural Parameters Affecting Tear Strength of the Fabrics Tents. Alexandria Engineering Journal, 57, 97-105. https://doi.org/10.1016/j.aej.2016.12.005

[24] Keyavlon Impex (2020) Polyester High Tenacity Yarn. http://www.kayavlon.com/phtyarn.htm

[25] Tyagi, G.K. (2010) 5-Yarn Structure and Properties from Different Spinning Techniques. In: Lawrence, C.A., Ed., Advances in Yarn Spinning Technology (Woodhead Publishing Series in Textiles), Woodhead Publishing, Sawston, 119-154.

[26] Tissera, N., Wijesena, R., Jayawickramage, R., De Silva, K.M. and Amaratunge, G. (2015) Hydrophobic Cotton Textile Surfaces Using an Amphiphilic Graphene Oxide (GO) Coating. Applied Surface Science, 324, 455-463. https://doi.org/10.1016/j.apsusc.2014.10.148

[27] Ryu, S.-R. and Lee, D.-J. (2001) Effects of Fiber Aspect Ratio, Fiber Content, and Bonding Agent on Tensile and Tear Properties of Short-Fiber Reinforced Rubber. Journal of Mechanical Science and Technology, 15, 35-43. https://doi.org/10.1007/BF03184796

[28] Property Information (2020) Young's Modulus and Specific Stiffness. http://www-materials.eng.cam.ac.uk/mpsite/properties/non-IE/stiffness.html

[29] Omnexus (2020) Stiffness. https://omnexus.specialchem.com/polymer-properties/properties/stiffness

[30] Prasad, B.M. and Sain, M.M. (2003) Mechanical Properties of Thermally Treated Hemp Fibers in Inert Atmosphere for Potential Composite Reinforcement. Materials Research Innovations, 7, 231-238. https://doi.org/10.1007/s10019-003-0258-y

[31] Müssig, J., Fischer, H., Graupner, N. and Drieling, A. (2010) Testing Methods for Measuring Physical and Mechanical Fibre Properties (Plant and Animal Fibres). In: Industrial Applications of Natural Fibres, Wiley, Hoboken, 267-309. https://doi.org/10.1002/9780470660324.ch13

[32] Nayak, R.K., Padhye, R. and Fergusson, S. (2012) Identification of Natural Textile Fibres. In: Handbook of Natural Fibres, Vol. 1, Elsevier Ltd., Amsterdam, 314-344. https://doi.org/10.1533/9780857095503.1.314

[33] Wiegerink, J.G. (1940) The Moisture Relations of Textile Fibres at Elevated Temperatures. Textile Research Journal, 10, 357-371. https://doi.org/10.1177/004051754001000901

[34] Li, S., Huang, J., Chen, Z., Chen, G. and Lai, Y. (2017) A Review on Special Wettability Textiles: Theoretical Models, Fabrication Technologies and Multifunctional Applications. Journal of Materials Chemistry A, Materials for Energy and Sustainability, 5, 31-55. https://doi.org/10.1039/C6TA07984A

[35] Cristaldi, G., Latteri, A., Recca, G. and Cicala, G. (2010) Woven Fabric Engineering. InTechOpen, London, 317-342.

[36] All of Textiles (2021) Jute Fibre. http://alloftextiles.com/aot_jute1.aspx

[37] Kaswell, E.R. (1963) Wellington Sears Handbook of Industrial Textiles. Massachusetts Institute of Technology (MIT) and Wellington Sears Company, Cambridge.

[38] Schellbach, S., Monteiro, S. and Drelich, J. (2015) A Novel Method for Contact Angle Measurements on Natural Fibers. Materials Letters, 164, 599-604. https://doi.org/10.1016/j.matlet.2015.11.039

[39] Textile Study Center (2021) Tensile Testing Terms and Tensile Testing Terms Definitions.

https://textilestudycenter.com/tensile-testing-terms-and-tensile-testing-terms-defin itions 
[40] Das, A. (2013) 3-Testing and Statistical Quality Control in Textile Manufacturing. In: Majumdar, A., Das, A., Alagirusamy, R. and Kothari, V.K., Eds., Process Control in Textile Manufacturing (Woodhead Publishing Series in Textiles), Woodhead Publishing, Sawston, 41-78.

[41] Neagu, R.C., Gamstedt, E.K. and Berthold, F. (2006) Stiffness Contribution of Various Wood Fibers to Composite Materials. Journal of Composite Materials, 40, 663-699. https://doi.org/10.1177/0021998305055276

[42] Morton, W. and Hearle, J. (2008) Physical Properties of Textile Fibres. 4th Edition, Woodhead Publishing Limited in Association with the Textile Institute, Cambridge, 163-167. https://doi.org/10.1533/9781845694425.163

[43] Moudood, A., Hall, W., Öchsner, A., Li, H., Rahman, A. and Francucci, G. (2019) Effect of Moisture in Flax Fibres on the Quality of Their Composites. Journal of Natural Fibers, 16, 209-224. https://doi.org/10.1080/15440478.2017.1414651

[44] Condoir (2020) The Importance of Humidity Control in Textile Processing. https://www.condair.co.uk/knowledge-hub/the-importance-of-humidity-control-in -textile-processing

[45] Li, X., Li, X., Tabil, L.G., Tabil, L.G., Panigrahi, S. and Panigrahi, S. (2007) Chemical Treatments of Natural Fiber for Use in Natural Fiber-Reinforced Composites: A Review. Journal of Polymers and the Environment, 15, 25-33.

https://doi.org/10.1007/s10924-006-0042-3 